\title{
The Role of Corporate Social Responsibility (CSR) in the Telecommunications Industry : An Overview of the Case of "Orange Tunisie" Operator
}

\author{
Ines Kahloul Nafti \\ Higher Institute of Management, Sousse, Tunisia \\ LAMIDED Laboratory \\ ineskahloul@gnet.tn
}

\begin{abstract}
The aim of this paper is to present new orientations for research in the field of information systems in the context of CSR. It offers an original conceptual analysis that integrates the CSR approach, which enables decision making, governance and strategic alignment of the Information and Communication Technologies (ICT), business and sustainability. In the actual context of the changing environment, a consensus regarding the need to change the pattern of development and growth comes to light. The CSR emerges as a new paradigm for economics. Its alliance with other economic concepts seems to become a necessity that aims at an approach for a global and sustainable performance for the company. As long as the firms' IT departments are energy consumers, it is of paramount importance to reconcile the new technologies and the CSR. Hence, in order for the company to stand out and increase its competitiveness, it has to think in terms of global, economic, social and environmental performance that would ensure a sustainable growth. The importance of the small and medium-sized enterprises in the Maghreb's economies and the challenges of the CSR implementation in such institutions should prompt us to wonder about the incentives and the engagement factors of managers in favor of the CSR while incorporating the ICT. It seems interesting, then ${ }_{2}$ to discover the way_to combine the ICT and the social practices, in order to ensure a sustainable performance for the company. An illustration of the case of "Orange Tunisie" operator will be advanced.
\end{abstract}

Keywords: CSR, ICT, performance, Governance, sustainable development

\section{Introduction}

The adoption of Information and Communication Technologies (ICT) is growing constantly. It characterizes our professional and personal environment. The use of ICT makes firms more competitive through reducing both production and transaction costs, and improving business coordination (Litan and Rivling, 2001; Brynjolfsson and Hitt, 2000). The employees are, to different degrees, users of these techniques and a source of improvement and development for the company. In fact, we are witnessing a general electronization wave of the company's functions. Today's numerous research projects confirm that the increasing networking in the organizations overwhelms the traditional managerial approaches. All jobs are affected by the spread of these technologies. However, these positive economic effects must be mitigated by the environmental impact of these technologies throughout their life cycle. Despite the potential contributions of ICT's to reduce the company's environmental impact, the use of technologies also has a negative influence on the environment because it consumes resources for production of energy in use, and generates end-of-life waste (Ait-Daoud et al., 2012). Thus, technologies are seen as both sources of problems and solutions (Fuchs, 2008). In an environmental context marked by global warming and the scarcity of non-renewable resources, the pressure exerted by the stakeholders on companies on this subject, is intensifying and as a result they are increasingly attentive to the impact of their activities on the environment (Melville, 2010).

The present article is meant to help understand the social appropriations of the new technologies in the company, and to suggest methods that can make the usage of these tools, by today and tomorrow's companies, efficient and acceptable. The major issue is to enable the orientation of the practices towards considering the social responsibility of the company in order to ensure the sustainability of the firm and its continuous development. As a first step, the article examines the extent to which ICT contributes in the improvement of the company's performance. As a second step, it tempts to explain the way this impact is dependent on the company's awareness of its social responsibility in the technological changes. 


\section{The direct Relationship between ICT and Performance}

Numerous works have been interested in the study of the investments on ICT and their impact on the companies' performance. Thus, Matmati (2001) qualifies the ICT as technological solutions bringing potential and important increase of the effectiveness of people and organizations. In fact, the ICT affect the working habits and methods, relationships within the company and even the structure of this latter. This can be seen through the improvement of the communication within the company and of the decision-making-process. The ICT's contribution can also be analyzed as a development of a specific capacity to the firm that offers the possibility to develop a competitive advantage over its competitors (Liang et al., 2010). At the organizational level, information technologies are widely known in literature for their contribution in the process innovation, because they lead to organization transformation (Besson and Rowe, 2011). The performance remains a complex notion; its understanding depends on many elements (intern and extern) that present a strong interdependence. In this direction, Matmati (2002) distinguishes between two branches that study the performance sources; the first belongs to the school of strategists and economists, and it explains the performance through external factors. The second is based on the organizations theory stipulating that the performance shall result in intern factors of the organization. The effectiveness improvement the ICT not only saves energy, but also leads to substantial profits. In fact, the majority of the available empirical researches shows that the effect of the ICT on productivity is positive and significant (Cardona et al., 2013). It is necessary to be aware that the emergence of new technological uses and the application of the new technologies make a challenge to enterprises. The link between ICT and performance is, then, very frequent even though it is not systematic.

ICT, Risk and Performance Influence: Because of the usage of the ICT, many consequences may come out. A significant increase of the amount of data may negatively influence the quality of work, the humane and relational environment as well as the economic performance. The implementation of technologies in an enterprise can accentuate the differences between generations, education level, and personal experiences with technological tools. In fact, according to their levels, ages or experiences, people would have contrasted forms of appropriation. This is why it is very important to make them aware of this and make them feel responsible. Hence, with the use of ICT, the enterprise may face the risk of its fragmentation into groups of people having different temporalities and rituals. The ICT accelerates this phenomenon for because of the unterritorializing (working at home, in one's car, etc) and the extra-temporality (working in the evening or at weekends) that it causes, it can weaken the power of the colleagues' shared-workplace and time. This fosters the emergence of different networks of heterogeneous people. This way, the ICT reveals and accentuates a risk for the cohesion and coherence of the enterprises' systems of organization (Silva and Hugon, 2009). Accordingly, accompanying measures and social responsibility efforts become a necessity to ensure a positive and a sustainable effect on the productivity of the enterprise and, thus, on its performance.

ICT and Group Performance: In front of the challenges of the new context that is characterized by novel requirements in terms of autonomy and reactivity, companies find it necessary to search for a new efficiency framework. This comes through the cooperation and coordination of the efforts in order to face the environmental conditions, particularly in the case of sophisticated and extensive organizations. In order to meet this requirement, it is crucial to exercise new technologies. In fact, the ICT enable the development of new group work models. Thanks to networking, a new coordination is established between individuals and organizations. The example of tele-working makes one of the working organization's forms with which one can contribute in the usage of technology to help in the performance enhancement.

ICT and Individual Performance: The application of ICT in companies can also contribute in the reinforcement of the employees' autonomy, and can provide easy access to all types to data. In fact, according to (Pichault and Nizet, 2008), the computerization of the structures decentralizes the decision-making process, and which leads to the reduction of the role of intermediates that is often played by managers. Hence, the employees' sense of autonomy is accentuated. This leads us to the notion of the "personalization" of the work relationship. As the study focuses on the individual, one can affirm that the introduction of ICT affects the different performance levels. In fact, the individual is in the centre of technological success of the organization. Performance, then, is promoted through internal factors, especially a good work atmosphere and adequate 
social conditions. On the other hand, the study of the role and the characteristics of the information systems within small companies have shown that the relationship with computer science is not evident with small organizations (Poulin and Tran, 2010; Deltour et al., 2014). This link between ICT and performance is sometimes influenced by certain factors particularly the ICT's applications number, complexity, the way they are implemented and their users' competence and conduct.

\section{The Renovated Relationship between ICT and Performance: The necessity of Accompanying measures and the Awareness about the CSR}

A number of previous works (Folacci and Lemoncini, 2003; Folacci, 2004) have focused on the existence of certain factors that can influence the diffusion and the practice of the ICT in a company in addition to its impact on the company's performance. Among these factors, one can cite the computerization of companies, their sizes, activity sectors and management modes. Even though this study of the determinants of the technology's users and diffusion is in favor of a contextualized approach of the process, it is still insufficient for the performance study (Folacci and Lemoncini, 2003). In fact, the introduction of information and communication technologies represents not only a financial constraint, but also behavioral one. The innovation theory stipulates that the principal challenge to all innovations is the change in behavior. No matter how strong is the willpower in the project, the usage of the ICT in the company provokes uncertainty to employees and overwhelms the working environment. Accordingly, Monod (2002) believes that the influence mechanism of the ICT on the companies' performance can be brought into focus through an indirect relationship that particularly motivates the individuals' behavior.

The qualitative and contextual Analyses of the relationship Between ICT and Performance: This work, then, considers the different qualitative and contextual dimensions of the ICT-performance relationship. This latter, can be determined and influenced by the behavior of the employees in a company when it comes to the use of ICT. This fact, hence, leads this analysis to shed light particularly on the CSR, which refers to the notion of social performance not only to the economic or financial one. The involvement of the executive and the employees as well, in this process, makes the appreciation of the ICT-performance relationship more sensible. One possible way to facilitate the achievement of this goal lies in the increase of the employees' motivation. This should make them improve and develop their performance. The focus, thus, is on divers' mediators whose enhancement makes it possible for the ICT to act positively on the company's performance. In this light, Brynjolfsson and Yang (1996); Grover et al. (1998) consider that the impact of the ICT is indirect and comes through the improvement of the process and the abilities that represent, what is referred to as the intangible intermediary profits. The introduction of ICT fosters also the freedom of communication, rapidity and the effectiveness in the information circulation in addition to the increase in the workers' autonomy and accountability.

The Role of Social Responsibility in the Use of ICT: Further measures for the application of ICT in companies are also needed. In fact, one can notice a change in the individuals' behavior. The reaction of the users (employees) to this technology determines the success of the ICT's integration in a company. This latter, then, has to create an organizational climate appropriate to the good reception of technologies (Klein et al., 1996). Accordingly, the future of the technological project is very dependent on the company's responsibility that has to create an encouraging climate for the adoption of ICT, and the employees should be at the center of focus. Their accountability should be in two ways. On the one hand, the utility of this technology perceived by the workers reflects the strength of their belief in its impact on the performance. On the second hand, comes the degree of their conviction in the technology's usage easiness. Discussing the contribution of this technology also seems crucial, especially that the implantation of ICT in an enterprise is often seen as a means of reinforcement of the supervision of the employees.

Green IT and CSR integrated approach's example : With Environmental requirements, Companies are encouraged to design, adopt and use Information Technologies (IT) known as "Green IT"1 or "eco-information

$1:$ « Green IT is an organization's ability to systematically apply environmental sustainability criteria (such as pollution prevention, product stewardship, use of clean technologies) to the design, production, sourcing, use 
technologies", abbreviated "eco-ICT (Molla et al., 2009). Hba et al. (2016) proposed a theoretical model of new generation management, consisting of a conceptual model of governance and strategic alignment of ICT based on the concepts of Green IT, CSR and stakeholder theory. In the same way, an innovative approach to ICT management is developped by Hba and El Manouar (2017) which is based on a simple principle aimed at the application of the basic concepts of sustainable development. They presented the enhanced model of ecostrategy, which is described as a new generation management model. It has been redesigned according to an integrated approach of Green IT and CSR. This approach provides companies with tools for the development of coherent and sustainable managerial strategies capable of enhancing overall performance and to explore new levels of transition towards renewed management modes to ensure a sustainable development. In other words, the model presented is considered as a Framework of managerial strategy for the governance and strategic alignment of ICT in a sustainable development approach.

In order to optimize the technological project, the company has to undertake certain accompanying measures; it is a question of setting up a steering committee that aims at ensuring a continuous assistance and maintenance. The involvement of workers in the process of the ICT integration makes another important measure. In fact, this involvement is for their accountability while fostering a positive perception of ICT, and this reduces the rejection risk. It seems, then, that in order to make the integration of ICT in a company successful, this latter has to face a major challenge: awareness management. In fact, awareness leads to create attitudes that determine behavior. According to Porter and Kramer (2006), CSR may be included in the company's strategy and eventually generate competitive advantage. For these authors, socially responsible corporations can be a source of mutual gains between business and society.

\section{Illustration of the case of "Orange Tunisie" operator}

Nowadays, in order to stand out and increase its competitiveness, the internationalized enterprise thinks in terms of a global performance (economic, social and environmental) that will assure a sustainable growth. This latter can be achieved through a long term approach for continuous progress, relying on shared practices within the company. This approach is to conciliate the following requirements: an economic development that takes into consideration the social (and societal) expectations of the stakeholders and that respects the environment. How about the case of the enterprises of the Maghreb and particularly of Tunisia after the revolution? An illustration of the case of "Orange Tunisie" operator is presented in the following section:

A Presentation of the "Orange Tunisie" Operator: Orange Tunisia is a Tunisian private communication operator. It is the fruit of an alliance between Orange SA (49\%) and Investec (51\%), property Mabrouk group. It is the second private telecommunication operator that has obtained a mobile telephony license in Tunisia and that has been launched in 2010. Like the other markets where Orange is present, the operator suggests a number of offering services related to Internet and telephony via Internet.

The CSR Integration in the Strategy of "Orange Tunisie" Operator: The operator relies in its approach on France Telecom Orange group, whose experience since nearly fifteen years consists in integrating the sustainable development's and the CSR's challenges in his corporation strategy. This is explained by the fact that the CSR represents an important vehicle for value creation for both of the stakeholders and the enterprise. Throughout time the company has been committed to numerous international deals aiming at strengthening the CSR's principles in its strategic approach. In 1996, it signed the charter environment of the ETNO (European Telecommunications Network Operators). In 2000, it adhered to the global UN Pact. CSR projects have been launched in the global framework of the access strategy to communication and to fight the digital divide in addition to reducing the energy consumption. One can cite as an example, the creation and the animation of the program of the young developers of mobile applications having as a principal objective to boost this employment sector, or the example of the campaign to raise the awareness of the staff towards everyday green actions (Bel Haj Ali, 2012). In the Tunisian digital company, Orange Tunisie assumes its responsibility to consolidate the social link and to bring the maximum number of the novel technologies'

and disposal of the IT technical infrastructure as well as within the human and managerial components of the IT infrastructure. » 
benefits. According to the company's managers, the CSR's integration in the strategic approach of the company makes an essential condition for its success and continuity (Jaidane and Beschaouch, 2013). These authors affirm that the CSR approach of the company goes beyond the citizens' engagement to move on to the adhesion of the top management and the different employees. They also assert that their motivation lies in the strong conviction that the CSR is a vehicle of innovation and of value creation for all the stakeholders of the company.

In order to make of this approach a success, accompanying measures seem to be necessary. It is all about recognizing and accompanying their employees, ensuring transparency, quality and security to customers, de facilitating the accessibility to benefits of the digital world, and finally innovating for the sake of a new ecocitizenship. The ultimate objective of "Orange Tunisie" is to become the reference for the CSR in Tunisia in the long term. It aims at ensuring that all stakeholders collaborate together, starting from the top management to all employees to arrive at the final customer. This goal makes it possible for this operator to participate in the economic development of the country and to be an innovation agent by its suggested services. The CSR notion, which has been developed these later years as a consequence of globalization, is concerned with all types of companies, all at the same degree. It represents the actions carried out by a company to achieve sustainable performances while taking into consideration the social and environmental impacts of its activity, and while ensuring the respect of the human rights, principles of the good governance and transparency. Having a CSR dimension, leads to speaking about a responsible and value creator employer, who has the ability to solve certain problems. It is about a long term work on the preservation not only of the peace and the social stability of the company itself, but also on ensuring the eco-citizenship awareness-raising of the employees and customers (Bel Haj Ali, 2012).

In other words, the responsible insists on the fact that the CSR approach within Orange Tunisie operator makes it possible, as well, to prevent the environmental and social thanks to a best management of risks, and thanks to training plans that consider the employees' profiles, and to a good management of abilities. In the Annual Report of Orange group (2015) about Social Responsibility, it is affirmed that the adhesion of "Orange Tunisie" to the global Pact of the United Nations has put it in a one-way path to the social responsibility of the company. By joining the 8.000 members spread on more than 135 countries, The Tunisian version of mobile operators is committed to respect and promote the ten fundamental principles of the global pact in the field of human rights, labor rights environmental protection and the fight against corruption. In this sense, Orange Tunisia continued to initiate projects related to the optimization of scarce natural resources and the respect for the environment, and this, in both CSR and Green IT approaches. After the e-pay sheet for its employees, Orange Tunisia implies its clients in its approach Environment, with the digital (Dematerialization of the paper invoice), made available in PDF format on their dedicated digital space (platform "Selfcare") via the internet. This green approach aims at promoting the culture of "zero paper" within Orange Tunisia and its Stakeholders but also at reducing paper consumption.

A Responsible-Governance-Based Approach: In their annual report of 2015, which is about the continuous development and the social responsibility, the directors of the Operator Orange look for providing a fair and balanced vision for the global performance of the group. The aim is to reconcile economic and social performance to customer service and to the benefit of all partners. In fact, the process of the elaboration of the report of social responsibility of 2015 respects the three principles (inclusion, materiality and reactivity) of the norm AA1000APS (2008), which is referential for the social responsibility of the enterprises based on the respect of the stakeholders' expectations. In order to apply its strategy of CSR and to be seen as a reliable operator by its stakeholders, Orange uses a structured approach and clear governance principles. These principles give special attention to the issues of corruption prevention and human rights' respect. The CSR approach of Orange enjoys an organization that involves all the co-workers or stakeholders. With the governance committee and the CSR, and attached to the executive board of the operator, Orange uses an organization that ensures the application of the CSR.

In order to be able to have an external angle of vision for its approach, every year Orange answers the questionnaire of non-financial rating agencies and maintains a regular dialogue with financial analysts and socially responsible investors. Thus, the CSR's activism in the telecommunications operator Orange addresses 
not only issues related to sustainable development, but mainly to corporate governance renewal issues. In this logic, it is clear from its reports and communique that a strong willingness to secure the specific human capital of employees and external partners. It's particularly about the sensitization of team members on a sense of belonging to the same entity in order to override the collective interest over individual interests.

\section{Conclusion}

In a context marked, on one hand, by the increasing adoption of CSR practices and, on the other, by the increasing use of technology, we have advanced that the use of ICT does help in the enhancement of the company's performance but only when it is accompanied by other investments and actions such as organizational changes or social accountability of the different stakeholders. In fact, enterprises face two major challenges: on the one hand, it is the capacity of managers to appropriate new tools and to reinforce their teams. On the other hand, it is their ability to integrate new generations which are bringing new expectations (best balance between the private and the professional life, respect of diversity and integration of disabled people, ethical redefinition of corporate cultures, reduction of the ecological impact of the enterprises' activities while using the ICT, etc). Nevertheless, certain studies have focused on the positive as well as negative effects of the ICT on the company's performance. The present research study aims at developing a conceptual framework to show that the ICT's contribution to the performance of SMEs cannot be done through a direct relationship. This contribution highlighted the necessity to complete the simplistic dimension of the ICT with a section relating to CSR's mechanisms. This leads us to the conclusion that technologies have to be thought about by enterprises not only at the technical level, but also at the organizational, humane and even social levels. The challenge is to enable practices to be oriented towards the awareness of the social responsibility of the enterprise. The case of "Orange Tunisie" examined above is a significant example to the study conducted in this work. It shows the importance of the social dimension in the explanation of the relationship between ICT and performance. This should lead us to discuss the issue of responsible governance.

We indicate that the CSR is voluntarily used by the companies to support employment relationships and optimize the wealth-creating technological tool. In order to sustain relationships and get the best of the company's critical resources, the Orange Operator makes of CSR a priority to guarantee and valorize the interpersonal relationships, and this would be in logic of respect for loyalty principles and a team-spirit promotion. This would result in co-specializing efficiently the human capital of workers thanks to a reciprocal learning of these latter's. The company applies the same promotion principles of durable relationships with its external partners. It would be interesting to find a methodology that associates modeling with performance indicators and cultural evolution. The reinforcement of the workers' competences goes through a development and a strengthening of the social training that the companies' executives have to support because of the challenges related to technologies of information on the medium and long term. The articulation of ICT and CSR is related to the issue of the enterprises' governance; it has to integrate the stakeholders in the decision process. Thus, CSR is used by companies to overcome the failures of shareholder governance. An empirical study on the motivation of managers adopting a sustainable and a responsible behavior can be enriching for the enlargement the analysis' scope.

Recommandations: The aim of our analysis is to contribute to the perception of an ICT responsible management, in order to provide a roadmap for the companies to create new models of green business, thought on sustainable resources. Although they do not make great part of a highly-polluting sector, telecommunication operators bear witness to the broadening of the scope of CSR to issues of corporate governance. In order to achieve the primary objective of CSR, which is the creation of value for all partners in the company (shareholders, employees, customers, suppliers and civil society); there must be the adoption of the materiality principle, which arbitrates between the various stakeholder interests and prioritizing CSR priorities. It is also about strengthening instrumental CSR in the service of a collective alignment of stakeholder interests with those of the firm. As such, it is a question of combining traditional considerations in terms of incentives and control of original reflections on effective and sustainable forms of mobilization of specific assets, in particular human assets. Within this framework, formal and informal mechanisms must be 
put in place within the company in order to "complement" the disciplinary shareholder governance mechanisms, which are now insufficient.

\section{References}

Ait-Daoud, S., Bourdon, I. \& Rodhain, F. (2012). La gestion responsable des technologies de l'information et de la communication (TIC): un isomorphisme institutionnel? Le cas de la gestion des déchets informatiques (e-déchets)", Proceedings of the 17th AIM Conference, 21-23 May, Bordeaux.

Annual Report of Orange group. (2015). About Corporate Social Responsibility.

Bel Haj Ali, A. (2012). Communiqué published in Webmangermenter news, 14-11.

Besson, P. \& Rowe, F. (2011). Perspectives sur le phénomène de la transformation organisationnelle. Systèmes d'Information et Management, 16(1), 3-34.

Brynjolfsson, E. \& Yang, S. (1996). Information Technology and Productivity, A Review of the Literature. Advances in Computers, 43, 179-214.

Brynjolfsson, E. \& Hitt, L.M. (2000). Beyond Computation: Information Technology, Organizational Transformation and Business Performance. Journal of Economic Perspectives, 14(4), 23-48.

Cardona, M., Kretschmer, T. \& Strobel, T. (2013). ICT and Productivity: Conclusions from the Empirical Literature. Information Economics and Policy, 25(3), 109-125.

Deltour, F., Farajallah, M. \& Lethiais, V. (2014). L'équipement des PME en systèmes ERP: une adoption guidée par les priorités stratégiques? Management International, 18(2), 155-168.

Folacci, E. (2004). La contribution des TIC à la performance des PME : une analyse bidimensionnelle. In EMCIS (European and Mediterranean Conference on Information Systems), Tunis, Tunisie, 25-27 July.

Folacci, E. \& Lemoncini, S. (2003). La diffusion et les usages des TIC dans les petites et les moyennes entreprises: une analyse comparative par taille et par secteur d'activité. Economies et Sociétés, Série Economie de l'entreprise, 13, 867-894.

Fuchs, C. (2008). The Implications of New Information and Communication Technologies for Sustainability. Environmental Development and Sustainability, 10(3), 291-309.

Grover, V., Teng, J., Segars, A. H. \& Fiedler, K. (1998). The Influence of Information technology Diffusion and Business Process Change on Perceived Productivity: The IS Executive's Perspective. Information and Management, 34(3), 141-159.

Hba, R., Bakkas, A., El Manouar, A. \& Janati Idrissi, M A. (2016). Eco-strategy: Towards a new generation managerial model based on Green IT and CSR. International Journal of Computer Science \& Information Technology, 8(2), 53-64.

Hba, R. \& El Manouar, A. (2017). Eco-strategy: CSR strategy and Green IT updated model for ICT management. International Journal of Scientific \& Engineering Research, 8(1), 123-130.

Jaidane, S. \& Beschaouch, Y. (2013). Orange Tunisie, employer socialement responsable. Human Resources Expo. Retrieved from http://www.exposervicesinternational.com/presentation/7.pdf

Klein, J., Katherine, J. \& Sorra Joann, S. (1996). The Challenge of Innovation Implementation. Academy of Management Review, 21(4), 1055-1080.

Liang, T. P., You, J. J. \& Liu, C. C. (2010). A Resource-based Perspective on Information Technology and Firm Performance: a Meta-Analysis. Industrial Management \& Data Systems, 110(8), 1138-1158.

Litan, R. \& Rivlin, A. (2001). Projecting the Economic Impact of the Internet. American Economic Review, 91(2), 313-317.

Matmati, M. (2001). Les enjeux de l'intranet dans la GRH. In Actes du XIIe congrès de l'AGRH, thème: La GRH dans/et/ou la société de l'information, Liège.

Matmati, M. (2002). L'Intranet RH, outil de la performance organisationnelle? In. Kalika M. E-GRH, évolution ou révolution?, Editions Liaisons, 91-122.

Melville, N. P. (2010). Information Systems Innovation for Environmental Sustainability. MIS Quarterly, 34(1), 1-21.

Molla, A., Pittayachawan, S., Corbitt, B. \& Deng, H. (2009). An International Comparison of Green IT Diffusion. International Journal of e-Business Management, 3(2), 3-23.

Monod, E. (2002). Internet et performance de l'entreprise : Etude de l'organisation industrielle de 104 PME en Loire Atlantique. In 7ème Congrès de l'AIM, 30 Mai-1er Juin, Hammamet, Tunisie. 
Pichault, F. \& Nizet, J. (2008). Les pratiques de Gestion des Ressources Humaines. Approaches contingent et politique, Editions du Seuil, Retrieved from http://hdl.handle.net/2268/75248.

Porter, M. E. \& Kramer, M. R. (2006). Strategy \& Society: the Link between Competitive Advantage and Corporate Social Responsibility. Harvard Business Review, 84(12), 78-92.

Poulin, D. \& Tran, S. (2010). Information and Communication Technology and Small and Medium Sized Enterprises: From Theory to Practice. Cambridge Scholars publishing, 1-189.

Silva, F. \& Hugon, S. (2009). Usage des TIC et RSE, nouvelles pratiques sociales dans les grandes entreprises. Report CIGREF-ORSE, 5-38. 